by roughly a kilocalorie or more. This line of reasoning dictates that the correct value of $Q_{c}^{*}$ is at least $-18 \mathrm{kcal}$ instead of the value of -14.1 as reported by the authors.

\section{Authors' Reply}

\section{J.G. SHAW AND W. A. OATES}

We were aware of Dr. Shewmon's earlier result concerning the temperature gradient redistribution of cementite in $\alpha$-iron and agree that this requires that $Q_{c}^{*}$ shall be greater than the heat of solution of $\mathrm{Fe}_{3} \mathrm{C}$

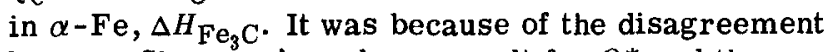
between Shewmon's and our result for $Q_{C}^{*}$ and the apparent discrepancy now raised by Dr. Shewmon that considerable effort was expended in the establishment of the reported value for $Q_{c}^{*}$. Since we are fairly confident of this result we are led to believe that $\Delta H_{\mathrm{Fe}_{3} \mathrm{C}}$ may be less than the 17 to $18 \mathrm{kcal}$ quoted by $\mathrm{Dr}$. Shewmon. Since values for this quantity lying between about 10 and $20 \mathrm{kcal}$ have been reported in the past we do not feel this unreasonable. Doubts about the indirect calculation of $\Delta \mathrm{H}_{\mathrm{Fe}_{3} \mathrm{C}}$ must continue in the absence of knowledge concerning any nonstoichiometry in $\mathrm{Fe}_{3} \mathrm{C}$. The "direct" methods of obtaining $\Delta H_{\mathrm{Fe}_{3} \mathrm{C}}$ must also still remain questionable when internal friction methods are used in which the peak height-concentration proportionality constant is not truly constant. It is interesting to note that the only calorimetric study of the reaction gave $\Delta H_{\mathrm{Fe}_{3} \mathrm{C}}=12.4$ kcal. The present value of $Q_{c}^{*}$ tends to support a value for $\Delta \mathrm{H}_{\mathrm{Fe}_{3} \mathrm{C}}$ of about this magnitude.

40. P. G. Shewmon: Trans. TMS-AIME, 1958, vol. 212, p. 642. 41. J. C. Swartz: Trans. TMS-AIME, 1969, vol. 245, p. 1083

\section{The Structure of Directionally Solidified Pb-Sn Eutectics Containing} \section{Antimony and Zinc Additions}

\section{G. GARMONG}

$T_{\text {HE directional solidification of binary eutectic alloys }}$ containing ternary additions may result in a breakdown of the regular plane-front structure into cells or dendrites. 'There have been two approaches to the problem of predicting the growth conditions of the breakdown of plane front growth. One is a direct extension of the Rutter-Chalmers constitutional supercooling model to multiphase alloys. ${ }^{2}$ With this model, the criterion of breakdown is given by $^{3}$

$$
G / R=-\left(\begin{array}{ll}
\frac{m}{D} & \frac{1-K_{0}}{K_{0}}
\end{array}\right) C_{0}
$$

where $G$ is the liquid-solid temperature gradient, $R$

G. GARMONG is Member of Technical Staff, North American Rockwell Science Center, Thousand Oaks, Calif.

Manuscript submitted September 22, 1971. the growth rate, $m$ the slope of the liquidus, $D$ the diffusion coefficient, $K_{0}$ a mean distribution coefficient, and $C_{0}$ the impurity content. In a second approach, Cline $^{4}$ and Hurle and Jakeman ${ }^{5}$ independently applied perturbation analysis to the liquid-solid interface. Cline ${ }^{4}$ derived an expression for the breakdown criterion as

$$
G / R=\frac{1}{2}\left(\frac{K_{s}}{K_{L}}+1\right)\left[\frac{C_{0}-C_{i}}{D} m^{*}+B \bar{C}_{0}\right]
$$

where $K_{s}$ is solid thermal conductivity, $K_{L}$ liquid thermal conductivity, $m^{*}$ the effective binary liquidus slope, $C_{0}-C_{i}$ the difference in binary initial and interface composition, $B$ a positive constant, and $\bar{C}_{0}$ the ternary impurity content.

Little direct data are available for evaluation of the merits of the two approaches in ternary systems. Diffusion coefficients are not accurately known in many cases, for instance. However, certain qualitative observations may be made. For example, Cline has shown that Eq. [2] may predict a range of stability wider than predicted by Eq. [1]. That is, in certain cases the melt composition may deviate from the binary eutectic and still produce a regular structure even with zero temperature gradient. The present work utilizes two systems, $\mathrm{Pb}-\mathrm{Sn}+\mathrm{Sb}$ and $\mathrm{Pb}-\mathrm{Sn}+\mathrm{Zn}$, in order to investigate the effects of ternary additions to eutectics. A series of melts was made for each ternary addition. The compositions chosen were such that each alloy was situated on the monovariant line departing the $\mathrm{Pb}-\mathrm{Sn}$ eutectic.

High-purity materials were used in the production of alloys: 99.999 pct pure $\mathrm{Pb}, \mathrm{Sn}$, and $\mathrm{Zn}$, and 99.99 pct pure Sb. Furnace charges of approximately $150 \mathrm{~g}$ were weighed to the nearest $0.01 \mathrm{~g}$ and melted in a closed graphite crucible under 1 atm of argon. The melts were heated to approximately $450^{\circ} \mathrm{C}$, stirred briefly with a stainless steel rod, held for $3 \mathrm{~min}$, and cast directly into quartz tubes. After cooling, each tube was inserted into a larger diameter quartz tube, and the assembly was evacuated, back-filled with $0.5 \mathrm{~atm}$ argon, and sealed. Up to six specimens at a time were directionally solidified vertically at rates of $0.4,0.7$, $1.1,2.2$, or $4.4 \mathrm{~cm}$ per $\mathrm{hr}$ by withdrawing them from a furnace whose center temperature was $400^{\circ} \mathrm{C}$. The temperature gradient at the melting point of the specimens was determined by thermocouples sealed into several specimens and was found to be $\sim 18^{\circ} \mathrm{C}$ per $\mathrm{cm}$, independent of solidification velocity at the low velocities used.

The resulting specimens were circular cylinders 0.8 $\mathrm{cm}$ in diam and $20 \mathrm{~cm}$ long. Transverse sections for metallography were taken at 4,10 , and $16 \mathrm{~cm}$ from the end first solidified. These sections were mechanically polished to Linde $A$ and electropolished in a solution of 2 parts (by volume) perchloric acid, 1 part butyl cellosolve, and 7 parts ethyl alcohol. Polishing voltages ranged from 12 to $18 \mathrm{v}$, and no subsequent etching was required. Every specimen examined showed no significant microstructural differences in the three sections taken, and it was concluded that steady state had been realized over at least the central portions of each specimen.

The type of structure observed in each alloy is indicated on a plot of $G / R$ vs impurity content for antimony and zinc additions in Figs. 1 and 2 , respectively. In 